\title{
Indole-3-Acetic Acid, Polyamines, and Phenols in Hardwood Cuttings of Recalcitrant-to-Root Wild Grapes Native to East Asia: Vitis davidii and Vitis kiusiana
}

\author{
Shuji Shiozaki, ${ }^{1}$ Masahiro Makibuchi, ${ }^{1}$ and Tsuneo Ogata $^{2}$ \\ ${ }^{1}$ Graduate School of Life \& Environmental Sciences, Osaka Prefecture University, 1-1 Gakuen-cho, Naka-ku, \\ Sakai, Osaka 599-8531, Japan \\ ${ }^{2}$ Faculty of Agriculture, Kochi University, Otsu 200, Monobe, Nankoku, Kochi 783-8502, Japan \\ Correspondence should be addressed to Shuji Shiozaki; ssgvo67@plant.osakafu-u.ac.jp
}

Received 4 July 2013; Revised 20 August 2013; Accepted 7 October 2013

Academic Editor: Bernd Schneider

Copyright (C) 2013 Shuji Shiozaki et al. This is an open access article distributed under the Creative Commons Attribution License, which permits unrestricted use, distribution, and reproduction in any medium, provided the original work is properly cited.

Levels of indole-3-acetic acid (IAA), free, conjugated, and bound polyamines (PAs), and phenols were estimated in the basal portion of hardwood cuttings of Vitis davidii and V. kiusiana in relation to rooting and compared with Vitis labruscana Bailey cv. Campbell Early. A high rate of root formation was observed in 'Campbell Early' cuttings 60 days after planting. However, none of the $V$. davidii and V. kiusiana cuttings formed roots. An increase in IAA contents was observed in 'Campbell Early' cuttings, but not in $V$. davidii and V. kiusiana, 60 days after planting. The content of free, conjugated, and bound PAs was either constant or decreased in 'Campbell Early' cuttings during planting and was especially decreased in conjugated putrescine and spermidine. An increase in free and conjugated putrescine was observed after planting in V. kiusiana cuttings. In the cuttings of $V$. davidii, only bound spermine increased after planting. The content of total phenols, orthodiphenols, total catechins, and gallocatechin derivatives decreased after planting in 'Campbell Early' cuttings. Orthodiphenols and total catechin contents increased in the cuttings of V. kiusiana, and gallocatechin derivatives increased in $V$. davidii. The relationships between these endogenous factors and the recalcitrant-to-root features of V. davidii and V. kiusiana cuttings are discussed.

\section{Introduction}

Vitis kiusiana Momiyama and V. davidii (Roman.) Foëx are dioecious wild grapes native to East Asia; the former habitat is to the southern region of Kyushu, Japan, and the latter is to a southern region from the Yellow River, China. V. kiusiana and $V$. davidii have glandular hair and aculei, respectively, on their canes. The mature berry size of $V$. kiusiana is around $11 \mathrm{~mm}$ in diameter, which is relatively large for species of wild grapes native to Japan. $V$. davidii bears larger berries (around $16 \mathrm{~mm}$ ) than $V$. kiusiana. The mature leaf size of $V$. kiusiana (ca $100 \mathrm{~cm}^{2}$ ) is relatively small in comparison with other grape cultivars (e.g., 'Campbell Early' is ca $198 \mathrm{~cm}^{2}$ ). In contrast, $V$. davidii is larger (ca $280 \mathrm{~cm}^{2}$ ). Although the leaf sizes of $V$. davidii and $V$. kiusiana are very different, their mature leaves are both cordate in shape. Galet [1], who developed a system for identifying grape varieties based on the shape of leaves and other organs, described that the deeper are the lobes of a mature grape leaf, the more evolved is the grape species. Therefore, $V$. kiusiana and $V$. davidii seem to be more primitive species of the wild grapes native to East Asia.

Efficient propagation methods, especially for female plants of desired genetic types, are needed for the practical use of these grapes. Cutting is a commercial practice for large-scale propagation in viticulture [2]. Adventitious root formation in cuttings is the most important morphogenesis affecting propagation success in cutting. Both $V$. kiusiana and $V$. davidii are grapes whose cuttings are recalcitrant to root. The detailed cause of their low rooting ability has not been elucidated.

Adventitious root formation is affected by environmental conditions and exogenous and endogenous biochemical compounds. Among the endogenous compounds, auxins play a central role in the root formation of several plants [3]. 
TABle 1: Size of hardwood cuttings of 'Campbell Early', Vitis davidii, and Vitis kiusiana.

\begin{tabular}{cccc}
\hline Year & Grapes & Length of cutting $(\mathrm{cm})$ & Basal end diameter of cutting $(\mathrm{mm})$ \\
\hline \multirow{2}{*}{2003} & Campbell Early & $11.8 \pm 0.1$ & $9.2 \pm 0.1$ \\
& V. davidii & $10.9 \pm 0.2$ & $7.7 \pm 0.2$ \\
\hline \multirow{2}{*}{2004} & V. kiusiana & $10.6 \pm 0.2$ & $8.4 \pm 0.2$ \\
& Campbell Early & $10.5 \pm 0.1$ & $10.1 \pm 0.3$ \\
& V. davidii & $12.7 \pm 0.3$ & $7.9 \pm 0.3$ \\
\hline
\end{tabular}

The exogenous supply of auxins (indole-3-butyric acid (IBA) or naphthaleneacetic acid) has been used for the efficient propagation of cuttings in many horticultural and forestry plants [3]. Polyamines (PAs) are known to affect morphogenesis in plants [4]. In the in vitro culture of woody plants such as poplar, hazel, and olive, PAs stimulated adventitious root formation from microshoots when they were treated with auxins $[3,5]$. On the other hand, exogenous PAs were reported to have no effect on adventitious root formation in Prunus avium shoot culture [6] and Vitis vinifera cuttings [7]. In mung bean hypocotyl cuttings, IBA stimulated root formation with increasing PA levels [4]. Biondi et al. [6] reported that PA biosynthesis inhibitors inhibited rooting from shoots of $P$. avium in vitro. These results indicate that at least endogenous PAs are involved in adventitious root formation. Endogenous biochemical compounds, which have been postulated as auxin synergists since the late 1960s, are phenolic compounds. The role of phenolic compounds in adventitious root formation is hypothesized to be in protecting the rooting-inducer endogenous auxin indole-3-acetic acid (IAA) from being destructed by peroxidase, which can act as an IAA oxidase [3]. However, the effect of endogenous phenolic compounds on adventitious root formation might be more complicated because the composition and concentration vary with the species and growth phase. Although the effect of an exogenous application of phloroglucinol, a monophenol, has been confirmed in adventitious root formation of some woody plants $[8,9]$, an inconsistency in its effect has been observed in apple cuttings in vitro $[10,11]$. Among the phenolic compounds, cinnamic acid acts to stimulate rather than inhibit the oxidation of IAA. In addition, as suggested by Wilson and Van Staden [12], low concentrations of phenolic compounds may promote adventitious root formation, while higher concentrations may inhibit them.

The aim of this work is to elucidate the endogenous factors affecting the rooting ability of hardwood cuttings of $V$. kiusiana and $V$. davidii. Levels of IAA, Pas, and phenolic compounds in cuttings were compared with those of cuttings of 'Campbell Early', an easy-to-root Vitis cultivar.

\section{Materials and Methods}

2.1. Plant Material and Cutting. Vitis labrusca Bailey ('Campbell Early'), V. kiusiana Momiyama, and V. davidii (Roman) Foëx were planted in a research field at Osaka Prefecture University (E $135^{\circ} 51^{\prime}, \mathrm{N} 34^{\circ} 54^{\prime}, 30 \mathrm{~m}$ asl.) and used in this experiment during 2003 and 2004 . Woody current canes with ca 6-8 nodes were obtained from these vines in late January of 2003, and in early January of 2004 and stored horizontally at $4^{\circ} \mathrm{C}$ in a plastic bag until cutting during each year. Cutting was conducted in early April in 2003 and late March in 2004. Cuttings with one bud were prepared from the stored canes, and the length and basal end diameter (an average of the major and minor axes) were measured. Data on the length and basal end diameter of the hardwood cuttings are shown in Table 1 . The cuttings were planted in vermiculite in a planting box ( $L 435 \mathrm{~mm} \times W 320 \mathrm{~mm} \times D 95 \mathrm{~mm})$ and placed in an unheated glasshouse. They were watered with $0.75 \mathrm{~L}$ tap water per planting box every 2-3 days. Observations on rooting were made at 60 days after planting during each year. All cuttings with roots $(>2 \mathrm{~mm}$ ) were classified as rooted cuttings, and the roots $(>2 \mathrm{~mm})$ were used to obtain mean root length $(\mathrm{cm})$. Percent callusing was estimated in 2003; cuttings with clearly visible callus on the base were classified as having callus.

2.2. Preparation of Samples for IAA, PA, and Phenol Analyses. The number of cuttings used for IAA, PA, and phenol analyses was 15-20,18, and 6, respectively, for each grape species and experimental period. The basal portions $(4 \mathrm{~cm})$ were collected from the cuttings on the planting day (day 0 ) and 60 days after planting. The lignified skins of the samples were removed. The level of IAA was analyzed using whole samples. Thin slices $(2 \mathrm{~mm})$ and middle portions $(2 \mathrm{~cm})$, which were cut from the middle part of the whole sample, were respectively used for PA and phenol analyses. Each sample was chopped into small pieces with scissors, immediately frozen in liquid nitrogen, and then stored at $-30^{\circ} \mathrm{C}$ until analysis.

2.3. Analysis of IAA. Analysis of IAA in the basal portion of cuttings was conducted in 2003. Samples (ca $10 \mathrm{~g}$ ) were immersed in $150 \mathrm{~mL}$ of cold $80 \%$ methanol containing $1 \mathrm{mM}$ butylated hydroxytoluene (BHT) and $0.01 \%$ ascorbic acid and stirred for $24 \mathrm{~h}$ at $4^{\circ} \mathrm{C}$. After filtration, the residue was washed three times with $50 \mathrm{~mL}$ of $80 \%$ methanol extraction solution. The combined filtrate was concentrated to the aqueous phase, which was then acidified to $\mathrm{pH} 2.8$ with $\mathrm{HCl}$ and partitioned three times against an equal volume of ethyl acetate containing $0.1 \mathrm{mM}$ BHT. The ethyl acetate phase was dried and redissolved in $3 \mathrm{~mL}$ of $0.1 \mathrm{M}$ Sorensen-Gomori phosphate buffer ( $\mathrm{pH} 8.0$ ), then it was placed on a column of polyvinylpyrrolidone $(18.7 \times 30 \mathrm{~mm})$. IAA was eluted in $40 \mathrm{~mL}$ of buffer from the column. The eluate was acidified to $\mathrm{pH} 3.0$ with $\mathrm{HCl}$ and partitioned three times against an equal volume of ethyl acetate containing $0.1 \mathrm{mM}$ BHT. The ethyl 
acetate phases were concentrated to dryness in vacuo and further purified by HPLC (Model 576: GL Science, Tokyo). The samples were eluted at a flow rate of $1 \mathrm{~mL} \mathrm{~min}^{-1}$ from a reverse-phase column (Shim-pack CLC-ODS, $4.6 \times 250 \mathrm{~mm}$ : Shimazu GLC, Tokyo) using a linear solvent gradient from $30 \%$ to $80 \%$ methanol in $0.1 \%$ acetic acid for $30 \mathrm{~min}$. IAA was monitored with a fluorescence detector (the excision and emission wavelengths were $285 \mathrm{~nm}$ and $365 \mathrm{~nm}$, resp.) (RF-550: Shimazu, Kyoto) and a fraction containing IAA was collected and dried.

IAA was analyzed by GC (GC-17A: Shimazu, Kyoto) equipped with quadratic MS (MS-QP5000: Shimazu, Kyoto). After conversion to methyl esters with diazomethane, the samples were dissolved in $3 \mu \mathrm{L}$ of methanol, and a $1 \mu \mathrm{L}$ aliquot was then injected onto a capillary column of DB-1 ( $5 \mathrm{~mm} \times$ $30 \mathrm{~m}$ : Agilent, Santa Clara). The column temperature was programmed to increase from $150^{\circ} \mathrm{C}(3 \mathrm{~min})$ to $280^{\circ} \mathrm{C}$ at $10^{\circ} \mathrm{C} \mathrm{min}^{-1}$. The He inlet pressure was $100 \mathrm{kPa}$ and the injector temperature was $285^{\circ} \mathrm{C}$. IAA was identified by gas chromatography-mass spectrometry and quantified by gas chromatography selected-ion monitoring; the monitored ion of IAA was the highest intensity ion, $m / z 130$. The analyses of IAA were conducted in triplicate.

2.4. Analysis of PAs. Analysis of PAs was conducted in 2003. The extraction procedure was a slightly modified method of that of Shiozaki et al. [13]. Samples (200 mg) were homogenized in cold $10 \%$ perchloric acid (PCA; one $\mathrm{mL} \cdot 0.1 \mathrm{~g}^{-1}$ sample) and maintained at $4^{\circ} \mathrm{C}$ for $30 \mathrm{~min}$. The extracts were centrifuged for $15 \mathrm{~min}$ at $25,000 \mathrm{~g}$, and the supernatant fraction was used for the determination of free PAs and PCA-soluble conjugated PAs. The pellet was washed in $5 \mathrm{~mL}$ of PCA, centrifuged for $15 \mathrm{~min}$ at 25,000 g, and then resuspended in the original volume of PCA by vortexing. The pellet suspension and the original supernatant $(0.2 \mathrm{~mL}$ each) were hydrolyzed for $18 \mathrm{~h}$ with $0.2 \mathrm{~mL}$ of $12 \mathrm{~N} \mathrm{HCl}$ at $110^{\circ} \mathrm{C}$ in a reaction vial. The hydrolysate was centrifuged and a $0.1 \mathrm{~mL}$ aliquot of the supernatant was dried in vacuo at $60^{\circ} \mathrm{C}$ and dissolved in $0.1 \mathrm{~mL}$ PCA. After dansylation of the extracts in the $0.1 \mathrm{~mL}$ PCA, the samples were analyzed by HPLC (Shim-pack CLC-ODS, $4.6 \times 250 \mathrm{~mm}$ : Shimazu GLC, Tokyo) equipped with a fluorescence detector (the excision and emission wavelengths were 365 and $510 \mathrm{~nm}$, resp.) using a linear solvent gradient of methanol in $\mathrm{pH} 3.5$ acetate buffer. The analysis of PAs was conducted in triplicate. The soluble conjugated PAs were estimated as the concentration of PAs in the hydrolysate of the original supernatant (free + conjugated PA), less than that of the free PAs.

2.5. Analysis of Phenols. Analysis of phenols was conducted in 2004. Samples $(1 \mathrm{~g})$ were homogenized in $50 \mathrm{~mL}$ cold $80 \%$ methanol using a biomixer (Nihonseiki, Tokyo). After filtration, the residue was washed twice with $50 \mathrm{~mL}$ of $80 \%$ methanol and filtered. The combined filtrate was adjusted with $150 \mathrm{~mL}$ of distilled water and used as a crude extract of the phenols.

The total phenols content was determined using the Folin-Ciocalteu method [14]. After elimination of methanol in the crude extracts $(50 \mathrm{~mL})$ in vacuo, the aqueous phase was adjusted to $10 \mathrm{~mL}$ and diluted five times with distilled water. The diluted sample was mixed with $1 \mathrm{~N}$ Folin-Ciocalteu reagent and then with $10 \%$ sodium carbonate 3 min later and placed at room temperature in darkness for $1 \mathrm{~h}$. The absorbance of the reactants at $530 \mathrm{~nm}$ was measured. The total concentration of phenolic compounds was estimated by a standard curve obtained with chlorogenic acid (Wako Pure Chemical, Osaka).

The ortho-diphenol content was determined using the method by Arnow [15]. One milliliter of the crude extract was mixed in order with $2 \mathrm{~mL}$ of $0.1 \mathrm{~N} \mathrm{HCl}, 2 \mathrm{~mL}$ of Arnow reagent, and $1 \mathrm{~mL}$ of $1 \mathrm{~N} \mathrm{NaOH}$. The sample was kept at room temperature in darkness for $20 \mathrm{~min}$, and then the content was spectrophotometrically evaluated at $530 \mathrm{~nm}$. Chlorogenic acid was used as a standard.

The total catechin units (catechin + procyanidine content) were analyzed using the crude extract diluted five times with $80 \%$ methanol. One milliliter of the diluted extract mixed with $2 \mathrm{~mL}$ of $1 \%$ vanillin in $70 \%$ sulfuric acid was placed at room temperature in darkness for $15 \mathrm{~min}$. The spectrophotometric quantification was performed at $500 \mathrm{~nm}$ using $(+)$-catechin as a standard.

Gallocatechin derivatives (GDs) were analyzed using the method described by McMurrough and McDowell [16]. One milliliter of crude extract was mixed with $4 \mathrm{~mL}$ of 4 dimethylaminocinnamaldehyde reagent and placed at room temperature in darkness for $10 \mathrm{~min}$. The GDs in the samples were quantified at $640 \mathrm{~nm}$ with reference to a standard curve obtained with $(+)$-catechin.

All the analyses of phenols were conducted in triplicate.

2.6. Statistical Analysis. Data on IAA, free Pas, and phenolic compounds were analyzed by analysis of variance and means were compared by Scheffé test at $P<0.05$ using StatView 5.0 (SAS Institute Inc.). Statistically significant differences of the data between the day of planting and 60 days after the planting of cuttings were tested with Student's $t$-test at $P<$ 0.05 and $P<0.01$.

\section{Results}

Withered cuttings were found only in V. davidii 60 days after cutting during each year; nine cuttings died in 2003 and two in 2004 (Table 2). The sprouting rate of 'Campbell Early' cuttings was greater than that of $V$. davidii and $V$. kiusiana during each year. In 'Campbell Early' cuttings, the sprouting rate in 2003 was $20 \%$ higher than that in 2004. Although all of the 'Campbell Early' cuttings rooted in 2003 and $62.5 \%$ of them rooted in 2004, no cuttings of $V$. davidii or $V$. kiusiana rooted during either year. The percent of rooting and root number per cutting of 'Campbell Early' were higher in 2003 compared with those in 2004. Callus in the basal portion of cuttings was observed in 'Campbell Early' and V. kiusiana, but not in $V$. davidii. The percent of callusing of $V$. kiusiana cuttings was $32.5 \%$ higher than that of 'Campbell Early'.

The IAA level in 'Campbell Early' cuttings was $1.3 \mathrm{ng} \cdot \mathrm{g}^{-1}$ fw at planting (day 0) and increased by more than nine times 60 days after planting (day 60) (Table 3). Although the IAA 
TABle 2: Adventitious root development of hardwood cuttings of 'Campbell Early', V. davidii, and V. kiusiana 60 days after planting.

\begin{tabular}{|c|c|c|c|c|c|c|c|c|}
\hline Year & \multicolumn{2}{|c|}{ Grapes $(n)$} & $\begin{array}{l}\text { Viable cuttings } \\
(n)\end{array}$ & $\begin{array}{c}\text { Sprouting } \\
(\%)\end{array}$ & $\begin{array}{c}\text { Rooting } \\
(\%)\end{array}$ & 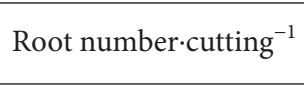 & $\begin{array}{l}\text { Root length } \\
(\mathrm{cm})\end{array}$ & $\begin{array}{c}\text { Callus formation } \\
(\%)\end{array}$ \\
\hline \multirow{3}{*}{2003} & $\begin{array}{l}\text { Campbell } \\
\text { Early }\end{array}$ & 40 & 40 & 95 & 100 & $9.5 \pm 1.6$ & $12.0 \pm 1.5$ & 47.5 \\
\hline & V. davidii & 17 & 8 & 0 & 0 & - & - & 0 \\
\hline & V. kiusiana & 20 & 20 & 10 & 0 & - & - & 80.0 \\
\hline \multirow{3}{*}{2004} & $\begin{array}{l}\text { Campbell } \\
\text { Early }\end{array}$ & 24 & 24 & 75 & 62.5 & $1.9 \pm 0.5$ & $11.8 \pm 1.1$ & - \\
\hline & V. davidii & 24 & 22 & 50 & 0 & - & - & - \\
\hline & V. kiusiana & 24 & 24 & 4 & 0 & - & - & - \\
\hline
\end{tabular}

TABLE 3: Indole-3-acetic acid content of hardwood cuttings of 'Campbell Early', Vitis davidii, and Vitis kiusiana at 0 and 60 days after planting (2003).

\begin{tabular}{lccc}
\hline Grapes & \multicolumn{2}{c}{ IAA $\left({\left.\mathrm{ng} \cdot \mathrm{g}^{-1} \mathrm{fw}\right)}\right.$} & Signif. between 0 and 60th day \\
\hline Campbell early & 0 & $12.0 \pm 2.6^{\mathrm{a}}$ & $*$ \\
V. davidii & $1.3 \pm 0.4^{\mathrm{b}}$ & $14.0 \pm 8.9^{\mathrm{a}}$ & Ns \\
V. kiusiana & $1.7 \pm 0.2^{\mathrm{b}}$ & $17.3 \pm 6.1^{\mathrm{a}}$ & Ns \\
\hline
\end{tabular}

Means with different letters in single rows are significantly different $(P<0.05)$.

Ns and $*$ indicate nonsignificant and significant at $P<0.05$.

level in V. davidii cuttings was similar to that of 'Campbell Early' at day 0, the level in V. kiusiana was five times higher than that of the other two grape varieties. No significant increase was found in the IAA level of V. davidii and V. kiusiana cuttings 60 days after planting.

Free PA contents of the cuttings are shown in Table 4. In all three grape species, the putrescine (Put) content of the cuttings was the highest and spermine (Spm) was the lowest at days 0 and 60 . The spermidine (Spd) content of $V$. davidii cuttings was significantly lower than that of 'Campbell Early' and V. kiusiana in both periods. At 60 days after planting, Spd levels in the cuttings of 'Campbell Early' and V. davidii had decreased by $80 \%$ and $75 \%$, respectively, of the levels at planting. Spm significantly decreased only in $V$. davidii 60 days after planting. In contrast, an increase in Put level was detected in V. kiusiana cuttings: the level at day 60 was 1.9 times higher than that at day 0 . The conjugated and bound PA levels were greater than that of free PAs, and Put was the predominant PA in each PA (Tables 5 and 6). The conjugated Put level of 'Campbell Early' significantly decreased 60 days after planting. In contrast, the conjugated Put level of $V$. Kiusiana at day 60 was 1.5 times higher than that at day 0 . The conjugated Spd level decreased in 'Campbell Early' and V. kiusiana cuttings 60 days after planting. In bound Put, there were no significant differences between the grape species, and over the duration of cutting in each species. Although the bound Spm level in V. davidii increased 60 days after planting, the bound Spd and Spm levels of V. kiusiana, and the bound level of Spm of 'Campbell Early', significantly decreased during the 60 days. The decrease in bound Spd level of V. kiusiana was notable.

There were no significant differences between the grape cuttings in terms of total phenols and ortho-diphenol levels at day 0 (Table 7). The content of total catechin units was significantly lower in $V$. davidii compared with 'Campbell Early' and V. kiusiana at day 0 . The content of GDs of $V$. davidii and V. kiusiana cuttings was about $22 \%$ and $56 \%$ of that in 'Campbell Early', respectively, at day 0. All phenols analyzed in 'Campbell Early' cuttings reduced to about 17$22 \%$ of the levels at day 0 during the 60 days after planting. In contrast, the ortho-diphenol and total catechin unit levels of $V$. kiusiana cuttings increased by about 1.9 and 1.5 times during the 60 days of planting, respectively. In $V$. davidii, only the GDs significantly increased 60 days after planting.

\section{Discussion}

The rooting ability of grape cuttings depends on the varieties and cultivars. Some cultivars of V. vinifera, and V. aestivalis cv. Norton and $V$. berlandieri $\times V$. rupestris $\mathrm{cv}$. 140-Ruggeri, are known to be difficult to root from their hardwood cuttings [17-19]; the lowest rooting rate was reported to be $23 \%$ in Norton cuttings. The poor rooting ability of V. kiusiana cuttings has also been reported by Mochioka et al. [20], although little useful information on the rooting ability of $V$. davidii hardwood cuttings is available. Mochioka et al. [20] observed that after breaking bud dormancy with a hot water treatment, $60 \%$ of hardwood cuttings of 'Muscat of Alexandria' formed adventitious roots after one month at $25^{\circ} \mathrm{C}$, but no V. kiusiana cuttings formed adventitious roots. Our results for V. kiusiana during 2003 and 2004 (Table 2) are in accord with those of Mochioka et al. [20] and show that $V$. davidii is also a very recalcitrant-to-root species like $V$. kiusiana.

Bud burst and callus formation at the base of cuttings may correlate with adventitious root formation [3]. The developing buds contribute as an origin of hormone-like substances needed for root formation. The bud burst of $V$. davidii and $V$. kiusiana was clearly inferior to that of 'Campbell Early' during 
TABLE 4: Free polyamines content in hardwood cuttings of 'Campbell Early', Vitis davidii, and Vitis kiusiana at 0 and 60 days after planting (2003).

\begin{tabular}{|c|c|c|c|c|}
\hline \multirow{2}{*}{ Polyamines } & \multirow{2}{*}{ Grapes } & \multicolumn{2}{|c|}{ Polyamines $\left(\mathrm{nmol} \cdot \mathrm{g}^{-1} \mathrm{fw}\right)$} & \multirow{2}{*}{ Signif. between 0 and 60th day } \\
\hline & & 0 & 60 & \\
\hline \multirow{3}{*}{ Put } & Campbell Early & $401.6 \pm 49.2^{\mathrm{a}}$ & $580.3 \pm 62.0^{\mathrm{a}}$ & Ns \\
\hline & V. davidii & $304.9 \pm 43.8^{\mathrm{a}}$ & $410.0 \pm 55.8^{\mathrm{a}}$ & Ns \\
\hline & V. kiusiana & $295.8 \pm 25.2^{\mathrm{a}}$ & $564.3 \pm 67.8^{\mathrm{a}}$ & $*$ \\
\hline \multirow{3}{*}{ Spd } & Campbell Early & $136.3 \pm 1.7^{\mathrm{a}}$ & $109.7 \pm 8.9^{\mathrm{a}}$ & * \\
\hline & V. davidii & $103.1 \pm 1.3^{\mathrm{b}}$ & $77.0 \pm 6.4^{\mathrm{b}}$ & * \\
\hline & V. kiusiana & $140.2 \pm 8.6^{\mathrm{a}}$ & $126.4 \pm 5.2^{\mathrm{a}}$ & Ns \\
\hline \multirow{3}{*}{ Spm } & Campbell Early & $72.3 \pm 2.3^{\mathrm{a}}$ & $72.7 \pm 1.8^{\mathrm{a}}$ & Ns \\
\hline & V. davidii & $75.5 \pm 1.5^{\mathrm{a}}$ & $67.4 \pm 0.4^{\mathrm{a}}$ & $* *$ \\
\hline & V. kiusiana & $75.5 \pm 2.4^{\mathrm{a}}$ & $70.5 \pm 1.9^{\mathrm{a}}$ & Ns \\
\hline
\end{tabular}

Means with different letters in single rows are significantly different $(P<0.05)$.

Ns, $*$, and $* *$ indicate nonsignificant and significant at $P<0.05$ and $P<0.01$, respectively.

Table 5: Conjugate Polyamines content in hardwood cuttings of 'Campbell Early', Vitis davidii, and Vitis kiusiana at 0 and 60 days after planting (2003).

\begin{tabular}{|c|c|c|c|c|}
\hline \multirow{2}{*}{ Polyamines } & \multirow{2}{*}{ Grapes } & \multicolumn{2}{|c|}{ Polyamines $\left(\mathrm{nmol}^{\left.-\mathrm{g}^{-1} \mathrm{fw}\right)}\right.$} & \multirow{2}{*}{ Signif. between 0 and 60 th day } \\
\hline & & 0 & 60 & \\
\hline \multirow{3}{*}{ Put } & Campbell Early & $1436.4 \pm 130.6^{\mathrm{a}}$ & $534.6 \pm 219.4^{\mathrm{b}}$ & $*$ \\
\hline & V. davidii & $1466.3 \pm 45.2^{\mathrm{a}}$ & $1335.4 \pm 240.5^{\mathrm{ab}}$ & Ns \\
\hline & V. kiusiana & $1382.8 \pm 91.1^{\mathrm{a}}$ & $2101.8 \pm 51.2^{\mathrm{a}}$ & $* *$ \\
\hline \multirow{3}{*}{ Spd } & Campbell Early & $203.5 \pm 21.9^{b}$ & $40.1 \pm 25.9^{\mathrm{a}}$ & $*$ \\
\hline & V. davidii & $333.9 \pm 22.7^{\mathrm{a}}$ & $432.7 \pm 143.3^{\mathrm{a}}$ & Ns \\
\hline & V. kiusiana & $400.4 \pm 32.7^{\mathrm{a}}$ & $178.7 \pm 22.3^{\mathrm{a}}$ & $* *$ \\
\hline \multirow{3}{*}{ Spm } & Campbell Early & $221.9 \pm 14.8^{\mathrm{a}}$ & $204.9 \pm 5.1^{\mathrm{a}}$ & Ns \\
\hline & V. davidii & $243.6 \pm 15.2^{\mathrm{a}}$ & $203.7 \pm 38.1^{\mathrm{a}}$ & Ns \\
\hline & V. kiusiana & $211.0 \pm 13.7^{\mathrm{a}}$ & $222.5 \pm 4.2^{\mathrm{a}}$ & Ns \\
\hline
\end{tabular}

Means with different letters in single rows are significantly different $(P<0.05)$.

Ns, $*$, and $* *$ indicate nonsignificant and significant at $P<0.05$ and $P<0.01$, respectively.

2003 and 2004. However, the cuttings of $V$. davidii did not form roots in 2004, even though the bud burst (sprouting) was $50 \%$. Therefore, at least in V. davidii, bud burst may not be an important factor affecting root formation. Many cuttings of $V$. kiusiana formed callus but no adventitious roots in 2003. It has been reported in cuttings of some woody plants that adventitious roots are not originated from callus, and the callus rather stop or delay adventitious root formation [21]. Štefančič et al. [22] also reported that thick callus postpones the root outgrowth in cherry rootstock cuttings. The vigorous callus formation likely characterizes the quiet low rooting ability of $V$. kiusiana cuttings.

Levels of IAA, the crucial endogenous factor for root initiation, in the cuttings of V. davidii, V. kiusiana, and 'Campbell Early' at planting were similar to those of 'Muscat Bailey A' hardwood cuttings reported by Kawai [23]. The level was significantly higher in $V$. kiusiana at cutting in comparison with $V$. davidii and 'Campbell Early' (Table 3). However, a significant increase in the level during planting was found only in 'Campbell Early'. The IAA level in grape hardwood cuttings at planting is higher in easy-to-root varieties than in difficult-to-root varieties $[19,24]$. In addition, IAA increases during the rooting stage in grape hardwood cuttings [23, 24]. Considering these reports and our results, an increase in the IAA level of cuttings during planting is a more important factor for rooting than the higher IAA level at planting. Štefančič et al. [25] observed in cherry leafy cuttings that the highest level of IAA accumulation in the cutting base at one day after IAA treatment did not stimulate the rooting formation. Auxins are involved not only in adventitious root formation but also in callusing of plant organs [26]. Therefore, a higher level of IAA at planting might stimulate callusing, an inhibitory factor for rooting, rather than adventitious root formation in $V$. kiusiana cuttings.

In $V$. vinifera cuttings, PCA-soluble conjugated PAs were detected as the predominant PA [7]. In the present study, however, conjugated and PCA-insoluble bound PAs were at a similar level in the cuttings, and those levels were higher than that of free PAs. Changes in the levels of these PAs depended on the species in this experiment. In 'Campbell Early', cuttings formed roots, free Spd, conjugated Put, and Spd significantly decreased and no PA increased during the 60 days after planting. In $V$. davidii, free Spd and Spm significantly decreased during the 60 days after planting, but bound Spm increased 
TABle 6: Bound Polyamines content in hardwood cuttings of 'Campbell Early', Vitis davidii, and Vitis kiusiana at 0 and 60 days after cutting (2003).

\begin{tabular}{|c|c|c|c|c|}
\hline \multirow{2}{*}{ Polyamines } & \multirow{2}{*}{ Grapes } & \multicolumn{2}{|c|}{ Polyamines $\left(\mathrm{nmol} \cdot \mathrm{g}^{-1} \mathrm{fw}\right)$} & \multirow{2}{*}{ Signif. between 0 and 60th day } \\
\hline & & 0 & 60 & \\
\hline \multirow{3}{*}{ Put } & Campbell Early & $1642.3 \pm 158.7^{\mathrm{a}}$ & $1292.3 \pm 62.5^{\mathrm{a}}$ & Ns \\
\hline & V. davidii & $1315.1 \pm 74.5^{\mathrm{a}}$ & $1301.4 \pm 328.7^{\mathrm{a}}$ & Ns \\
\hline & V. kiusiana & $1555.2 \pm 293.9^{\mathrm{a}}$ & $1305.2 \pm 110.8^{\mathrm{a}}$ & Ns \\
\hline \multirow{3}{*}{ Spd } & Campbell Early & $249.8 \pm 39.4^{\mathrm{a}}$ & $165.7 \pm 10.0^{\mathrm{a}}$ & Ns \\
\hline & V. davidii & $255.8 \pm 49.9^{\mathrm{a}}$ & $156.9 \pm 10.1^{\mathrm{ab}}$ & Ns \\
\hline & V. kiusiana & $301.7 \pm 31.9^{\mathrm{a}}$ & $118.0 \pm 10.2^{\mathrm{b}}$ & $* *$ \\
\hline \multirow{3}{*}{ Spm } & Campbell Early & $278.4 \pm 11.8^{\mathrm{a}}$ & $242.8 \pm 3.1^{b}$ & $*$ \\
\hline & V. davidii & $241.6 \pm 1.8^{\mathrm{b}}$ & $278.4 \pm 6.0^{\mathrm{a}}$ & $* *$ \\
\hline & V. kiusiana & $273.9 \pm 4.7^{\mathrm{ab}}$ & $234.6 \pm 0.4^{\mathrm{b}}$ & * \\
\hline
\end{tabular}

Means with different letters in single rows are significantly different $(P<0.05)$.

Ns, $*$, and $* *$ indicate nonsignificant and significant at $P<0.05$ and $P<0.01$, respectively.

TABle 7: Content of phenolic compounds in hardwood cuttings of 'Campbell Early', Vitis davidii, and Vitis kiusiana at 0 and 60 days after cutting (2004).

\begin{tabular}{|c|c|c|c|c|}
\hline \multirow{2}{*}{ Phenols } & \multirow{2}{*}{ Grapes } & \multicolumn{2}{|c|}{ Days after cutting } & \multirow{2}{*}{ Signif. between 0 and 60th day } \\
\hline & & 0 & 60 & \\
\hline \multirow{3}{*}{ Total phenols (chlorogenic acid equi. $\mathrm{mg} \cdot \mathrm{g}^{-1} \mathrm{fw}$ ) } & Campbell Early & $20.5 \pm 16.2^{\mathrm{a}}$ & $4.2 \pm 0.4^{\mathrm{c}}$ & $* *$ \\
\hline & V. davidii & $13.6 \pm 3.2^{\mathrm{a}}$ & $14.3 \pm 1.0^{\mathrm{b}}$ & Ns \\
\hline & V. kiusiana & $16.0 \pm 0.2^{\mathrm{a}}$ & $22.3 \pm 2.4^{\mathrm{a}}$ & Ns \\
\hline \multirow{3}{*}{ Orthodiphenols (chlorogenic acid equi. $\mathrm{mg} \cdot \mathrm{g}^{-1} \mathrm{fw}$ ) } & Campbell Early & $3.6 \pm 0.4^{\mathrm{a}}$ & $0.6 \pm 0.2^{\mathrm{b}}$ & $* *$ \\
\hline & V. davidii & $2.5 \pm 0.2^{\mathrm{a}}$ & $5.7 \pm 1.2^{\mathrm{a}}$ & Ns \\
\hline & V. kiusiana & $3.3 \pm 0.1^{\mathrm{a}}$ & $6.4 \pm 1.1^{\mathrm{a}}$ & * \\
\hline \multirow{3}{*}{ Total catechin units (+catechin equi. $\mathrm{mg} \cdot \mathrm{g}^{-1} \mathrm{fw}$ ) } & Campbell Early & $6.2 \pm 0.1^{\mathrm{a}}$ & $1.2 \pm 0.1^{\mathrm{c}}$ & $* *$ \\
\hline & V. davidii & $4.0 \pm 0.3^{\mathrm{b}}$ & $4.7 \pm 0.1^{\mathrm{b}}$ & Ns \\
\hline & V. kiusiana & $5.4 \pm 0.2^{\mathrm{a}}$ & $7.9 \pm 0.4^{\mathrm{a}}$ & $* *$ \\
\hline \multirow{3}{*}{ Gallocatechin derivatives (+catechin equi. $\mathrm{mg}^{-1} \mathrm{~g}^{-1} \mathrm{fw}$ ) } & Campbell Early & $3.6 \pm 0.5^{\mathrm{a}}$ & $0.8 \pm 0.01^{\mathrm{b}}$ & $* *$ \\
\hline & V. davidii & $0.8 \pm 0.1^{\mathrm{b}}$ & $2.2 \pm 0.2^{\mathrm{ab}}$ & $* *$ \\
\hline & V. kiusiana & $2.0 \pm 0.2^{\mathrm{b}}$ & $4.2 \pm 0.9^{\mathrm{a}}$ & Ns \\
\hline
\end{tabular}

Means with different letters in single rows are significantly different $(P<0.05)$.

Ns, $*$, and $* *$ indicate nonsignificant and significant at $P<0.05$ and $P<0.01$, respectively.

by 1.2 times the level of the cuttings at day 0 . A noteworthy change in PA levels was found in V. kiusiana cuttings. Free and conjugated Put increased, rather than decreased, 60 days after cutting; these levels at day 60 were 1.9 times and 1.5 times higher than that at day 0 , respectively. An increase in free PAs has been observed in the early inductive phase of rooting in some plants [5, 27]. Bartolini et al. [28] also demonstrated with Vitis rootstock '140 Ruggeri' cuttings that an increase in free Put could be correlated with the formation of root primordia. A comparison of the levels of free PAs between day 0 and day 60 showed no significant increase even in 'Campbell Early' cuttings under our experimental conditions. However, an increase in free PA levels might has been observed at an earlier period than day 60 because most roots would have already emerged by day 60 . Tiburcio et al. [29] observed a high Put: Spd + Spm ratio in tobacco thin cell layers in vitro when the root differentiated and concluded that Put is a good marker for root differentiation. Bartolini et al. [28] examined the effect of pretreatments such as water dipping and cold storage on the rooting of grape cuttings and observed that the ratio of Put: Spd + Spm (in the free fraction) was higher in effective rooting treatments, even at planting. In the present study, the ratio (in the free fraction) was 1.9, 1.7, and 1.4 for 'Campbell Early', V. davidii, and V. kiusiana cuttings at planting, respectively, and 3.2, 2.8, and 2.9 at 60 days after planting, respectively. This result indicates that the ratio of Put: Spd + Spm (in the free fraction) can be an indicator of the rooting ability of these species.

Conjugated PAs, as well as free PAs, were found to accumulate in Chrysanthemum leaf explants on a medium promoting root formation, followed by a decrease during the period of root emergence [30,31]. In addition, changes in the levels were more rapid and substantial in the conjugated PAs than in the free PAs. In the present study, changes in the levels of conjugated PAs were more distinctive than those of free PAs in 'Campbell Early' cuttings (Tables 4 and 5). Although a decrease in Spd level was observed in free PAs, both Spd and Put decreased in the conjugated PAs. The most notable 
was that the decreasing rate was greater in conjugated PAs than in the free form. This substantial decrease in conjugated PAs after root emergence (day 60) seems to be a feature in the rooting process of grape cuttings. In $V$. davidii and V. kiusiana cuttings, both of which formed no roots during the 60 days of cutting, constant or increased levels in conjugated PAs were observed (Table 5).

Each conjugated and bound PA is a metabolite of free PAs. Most conjugated PAs are linked covalently with low molecular weight compounds, such as phenols, or noncovalently with high molecular weight compounds, such as proteins, whereas most bound PAs are covalently linked to proteins or cell walls. It is chemically impossible for conjugated PAs to be metabolized directly to the bound form. The function of bound PAs is poorly understood in plants. The most distinctive changes in bound PAs were observed in Spm in all species (Table 6). In V. davidii cuttings, the increase in bound Spm may have partly resulted from the metabolism of the free form. However, it is difficult to rationalize the decrease in bound PAs found in 'Campbell Early' and V. kiusiana with respect to PA metabolism or the adventitious rooting of cuttings. Similar changes in bound PAs found in 'Campbell Early' and V. kiusiana would not explain the difference in adventitious root formation.

Gallic acid, catechin, and gallocatechin were identified as simple phenols in the stem of $V$. vinifera [32]. In the present study, catechins, GDs, and ortho-diphenols were colorimetrically detected, although gallic acid derivatives, which were analyzed using Neu's reagent, were detected only at day 0 and the levels were extremely low compared with those of the other phenols (data not shown). At planting, the levels of total catechins were significantly lower in $V$. davidii, and levels of GDs were significantly lower in $V$. davidii and V. kiusiana compared with those of 'Campbell Early' (Table 7). More contrasting results of phenol levels in the cuttings were found in changes in the levels during the 60 days after planting between 'Campbell Early' and the other two species. Each phenol, including total phenols, decreased to less than $22 \%$ of the level at day 0 in 'Campbell Early' cuttings 60 days after cutting. On the other hand, although the level of total phenols was constant in cuttings of $V$. davidii and V. kiusiana, GDs increased in $V$. davidii, and ortho-diphenols and total catechins increased in V. kiusiana 60 days after cutting (Table 7). In other plant cuttings, a positive effect of phenols such as phloroglucinol and chlorogenic acid has been observed in rooting $[9,12]$. The rationale of the positive effect on rooting is that phenols can prevent oxidative degradation of auxins by peroxidase. Ortho-diphenols and their derivatives, such as catechol, chlorogenic acid, and ferulic acid, are potent inhibitors of peroxidase $[33,34]$. Catechin and gallocatechin can also prevent peroxidase-catalyzed auxin oxidation [35]. Somkuwar et al. [36] suggested that high levels of phenols in grape rootstock cuttings at planting probably correlate with the formation of root primordia and elongation of the roots. The high level of gallocatechin found at cutting in 'Campbell Early' cuttings may play a role in the prevention of IAA oxidation.

However, the role of phenols accumulated in cuttings during planting seems to be more complicated and depends on the plant materials and rooting phase: induction, initiation of root primordial, and root emergence. Nag et al. [37] found in mung bean cuttings that the total phenol level increased by the treatment of IBA, which stimulate rooting, in the induction and late initiation phase, followed by decreasing at emergency phase. A sharp and transient increase in phenols induced by IBA treatment was also observed in date palm off shoot cuttings [38]. On the other hand, a decrease in the levels of chlorogenic acid and epicatechin was observed regardless of the treatment of IBA in cherry root stock cuttings [25]. In the present study, changes in the levels of phenols negatively correlated with that of IAA levels in the cuttings of 'Campbell Early', the only species of grape that formed roots in this experimental condition. In V. davidii and V. kiusiana cuttings, no significant increase in IAA levels was found despite the fact that phenol levels increased during the 60 days after planting. Overaccumulation of hydroxycinnamic acids such as chlorogenic acid and ferulic acid was observed in the cuttings of chestnut clone with low rooting ability in the period of four days after planting, while the concentration of these acids was decreased in the clone with higher rooting ability [39]. This observation and our results suggest that accumulated phenols during planting of cuttings act as an inhibitor rather than an inducer of rooting via the prevention of IAA oxidation. This supports the notion that a higher concentration of phenols inhibits rooting, which was suggested by Wilson and Staden [12].

Finally, our research revealed that the levels and changes in endogenous factors affecting the rooting of cuttings differ between easy-to-root and recalcitrant-to-root grape species. Moreover, it should be noted that these factors differ even between the cuttings of two recalcitrant-to-root grape species. The individual features of endogenous factors would benefit the development of efficient propagation methods for cuttings of $V$. davidii and V. kiusiana.

\section{Abbreviations}

IAA: Indole-3-acetic acid

IBA: Indole-3-butylic acid

PAs: Polyamines

Put: Putrescine

Spd: Spermidine

Spm: Spermine.

\section{References}

[1] P. Galet, A Practical Amepelography, L.T. Morton, translate in English, 1979, Cornell University Press, Ithaca, NY, USA, 1979.

[2] R. J. Weaver, Grape Growing, Wiley-InterScience, NY, USA, 1976.

[3] H. T. Hartmann, D. E. Kester, F. T. Davis, and R. L. Geneve, Plant Propagation: Principles and Practices, Prentice Hall, Upper Saddle River, NJ, USA, 6th edition, 1997.

[4] A. W. Galston and H. E. Flores, "Polyamines and plant morphogenesis," in Biochemistry and Physiology of Polyamines in Plants, R. D. Slocum and H. E. Flores, Eds., CRC press, London, 1991.

[5] J. F. Hausman, C. Kevers, and T. Gaspar, "Involvement of putrescine in the inductive rooting phase of poplar shoots raised in vitro," Physiologia Plantarum, vol. 92, no. 2, pp. 201-206, 1994. 
[6] S. Biondi, T. Diaz, I. Iglesias, G. Gamberini, and N. Bagni, "Polyamiens and ethylene in relation to adventitious root formation in Prunus avium shoot cultures," Physiologia Plantarum, vol. 78, no. 3, pp. 474-483, 1990.

[7] L. Geny, R. Dalmasso, and M. Broquedis, "Polyamines and adventitious root formation in Vitis vinifera L.," Journal International des Sciences de la Vigne et du Vin, vol. 36, no. 2, pp. 97-102, 2002.

[8] S. K. Nandi, L. M. S. Palni, and H. C. Rikhari, "Chemical induction of adventitious root formation in Taxus baccata cuttings," Plant Growth Regulation, vol. 19, no. 2, pp. 117-122, 1996.

[9] Q. Wang, "Factors affecting rooting of microcuttings of the pear rootstock BP10030," Scientia Horticulturae, vol. 45, no. 3-4, pp. 209-213, 1991.

[10] D. J. James and I. J. Thurbon, "Shoot and root initiation in vitro in the apple rootstock M9. and the promotive effects of phloroglucinol," Journal of Horticultural Science, vol. 56, no. 1, pp. 15-20, 1981.

[11] R. H. Zimmerman and O. C. Broome, "Phloroglucinol and in vitro rooting of apple cultivar cuttings," Journal of American Society For Horticultural Science, vol. 106, no. 5, pp. 648-652, 1981.

[12] P. J. Wilson and J. Van Staden, "Rhizocaline, rooting co-factors, and the concept of promoters and inhibitors of adventitious rooting-a review," Annals of Botany, vol. 66, no. 4, pp. 479490, 1990.

[13] S. Shiozaki, T. Ogata, and S. Horiuchi, "Endogenous polyamines in the pericarp and seed of the grape berry during development and ripening," Scientia Horticulturae, vol. 83, no. 1, pp. 33-41, 2000.

[14] V. L. Singleton and J. A. Rossi Jr, "Colorimetry of total phenolics with phosphomolybdic phosphotungstic cid reagents," American Journal of Enology and Viticulture, vol. 16, no. 3, pp. 144-158, 1965.

[15] L. E. Arnow, "Colorimetirc determination of the components of 3, 4-dihydroxyphenylalaninetyrosine mixtures," The Journal of Biological Chemistry, vol. 118, pp. 531-537, 1937.

[16] I. McMurrough and J. McDowell, "Chromatographic separation and automated analysis of flavanols," Analytical Biochemistry, vol. 91, no. 1, pp. 92-100, 1978.

[17] H. Çoban, "Determination of polyphenol oxidase activity during rooting in cutting of some grape varieties (Vitis vinifera L.)," Asian Journal of Chemistry, vol. 19, no. 5, pp. 4020-4024, 2007.

[18] K. Keeley, J. E. Preece, B. H. Taylor, and I. E. Dami, "Effects of high auxin concentrations, cold storage, and cane position on improved rooting of Vitis aestivalis michx. Norton cuttings," American Journal of Enology and Viticulture, vol. 55, no. 3, pp. 265-268, 2004.

[19] H. Kracke, G. Cristoferi, and B. Marangoni, "Hormonal changes during the rooting of hardwood cuttings of grapevine rootstocks," American Journal of Enology and Viticulture, vol. 32, no. 2, pp. 135-137, 1981.

[20] R. Mochioka, Y. Oda, and M. Tsubakimoto, "Relationship between rooting difficulty of cuttings and content of phenolic compounds in shoots of the Japanese wild grape Vitis kiusiana momiyama," American Society for Enology and Viticulture Japan, vol. 13, pp. 2-8, 2002.

[21] W. Spethmann and A. Hamzah, "Growth hormone induced root system types in cuttings of some broad leaved tree species," Acta Horticulturae, vol. 226, pp. 601-605, 1988.
[22] M. Štefančič, F. Štampar, and G. Osterc, "Influence of IAA and IBA on root development and quality of Prunus "GiSelA 5 " leafy cuttings," HortScience, vol. 40, no. 7, pp. 2052-2055, 2005.

[23] Y. Kawai, "Effects of exogenous BAP, $\mathrm{GA}_{3}$, and ABA on endogenous auxin and rooting of grapevine hardwood cuttings," Journal of the Japanese Society for Horticultural Science, vol. 66, no. 1, pp. 93-98, 1997.

[24] M. Kelen and G. Ozkan, "Relationships between rooting ability and changes of endogenous IAA and ABA during the rooting of hardwood cuttings of some grapevine rootstocks," European Journal of Horticultural Science, vol. 68, no. 1, pp. 8-13, 2003.

[25] M. Štefančič, F. Štampar, R. Veberič, and G. Osterc, “The levels of IAA, IAAsp and some phenolics in cherry rootstock "GiSelA 5 " leafy cuttings pretreated with IAA and IBA," Scientia Horticulturae, vol. 112, no. 4, pp. 399-405, 2007.

[26] A. D. Krikorian, "Hormones in tissue culture and micropropagation," in Plant Hormones: Physiology, Biochemistry and Molocular Biology, P. J. Davies, Ed., Kluwar, London, UK, 2nd edition, 1995.

[27] Z.-H. Liu, W.-C. Wang, and Y.-S. Yen, "Effect of hormone treatment on root formation and endogenous indole-3-acetic acid and polyamine levels of Glycine max cultivated in vitro," Botanical Bulletin of Academia Sinica, vol. 39, no. 2, pp. 113-118, 1998.

[28] G. Bartolini, M. A. Toponi, and P. Pestelli, "Free polyamine variations in rooting of Vitis rootstock 140 Ruggeri," Advances in Horticultural Science, vol. 23, no. 2, pp. 113-117, 2009.

[29] A. F. Tiburcio, T. Altabella, A. Borrell, and C. Masgrau, "Polyamine metabolism and its regulation," Physiologia Plantarum, vol. 100, no. 3, pp. 664-674, 1997.

[30] M. Aribaud, M. Carré, and J. Martin-Tanguy, "Polyamine metabolism and in vitro cell multiplication and differentiation in leaf explants of Chrysanthemum morifolium ramat," Plant Growth Regulation, vol. 15, no. 2, pp. 143-155, 1994.

[31] M. Aribaud, C. Kevers, J. Martin-Tanguy, and T. Gaspar, "Low activity of amine-oxidases and accumulation of conjugated polyamines in disfavour of organogenic programs in Chrysanthemum leaf disc explants," Plant Cell, Tissue and Organ Culture, vol. 55, no. 2, pp. 85-94, 1998.

[32] V. Amico, V. Barresi, R. Chillemi et al., "Bioassay-guided isolation of antiproliferative compounds from grape (Vitis vinifera) stems," Natural Product Communications, vol. 4, no. 1, pp. 27-34, 2009.

[33] O. Faivre-Rampant, J.-P. Charpentier, C. Kevers et al., "Cuttings of the non-rooting rac tobacco mutant overaccumulate phenolic compounds," Functional Plant Biology, vol. 29, no. 1, pp. 6371, 2002.

[34] T. T. Lee, A. N. Starratt, and J. J. Jevnikar, "Regulation of enzymic oxidation of indole-3-acetic acid by phenols: structure-activity relationships," Phytochemistry, vol. 21, no. 3, pp. 517-523, 1982.

[35] J. Méndez and M. C. Mato, "Methyl gallate and related polyphenols as auxin protectors," Phytochemistry, vol. 44, no. 1, pp. 4143, 1997.

[36] R. G. Somkuwar, D. D. Bondage, M. S. Surange, and S. D. Ramteke, "Rooting behaviour, polyphenol oxidase activity, and biochemical changes in grape rootstocks at different growth stages," Turkish Journal of Agriculture and Forestry, vol. 35, no. 3, pp. 281-287, 2011.

[37] S. Nag, K. Saha, and M. A. Choudhuri, "Role of auxin and polyamines in adventitious root formation in relation to changes in compounds involved in rooting," Journal of Plant Growth Regulation, vol. 20, no. 2, pp. 182-194, 2001. 
[38] A. Qaddoury and M. Amssa, "Effect of exogenous indole butyric acid on root formation and peroxidase and indole-3-acetic acid oxidase activities and phenolic contents in date Palm offshoots," Botanical Bulletin of Academia Sinica, vol. 45, no. 2, pp. 127-131, 2004.

[39] G. Osterc, M. Štefančič, A. Solar, and F. Štampar, "Phenolic content in cuttings of two clones of hybrid chestnut (Castanea crenata $\mathrm{x}$ Castanea sativa) in the first days after cutting severance," Acta Agriculturae Scandinavica B, vol. 58, no. 2, pp. 162-168, 2008. 

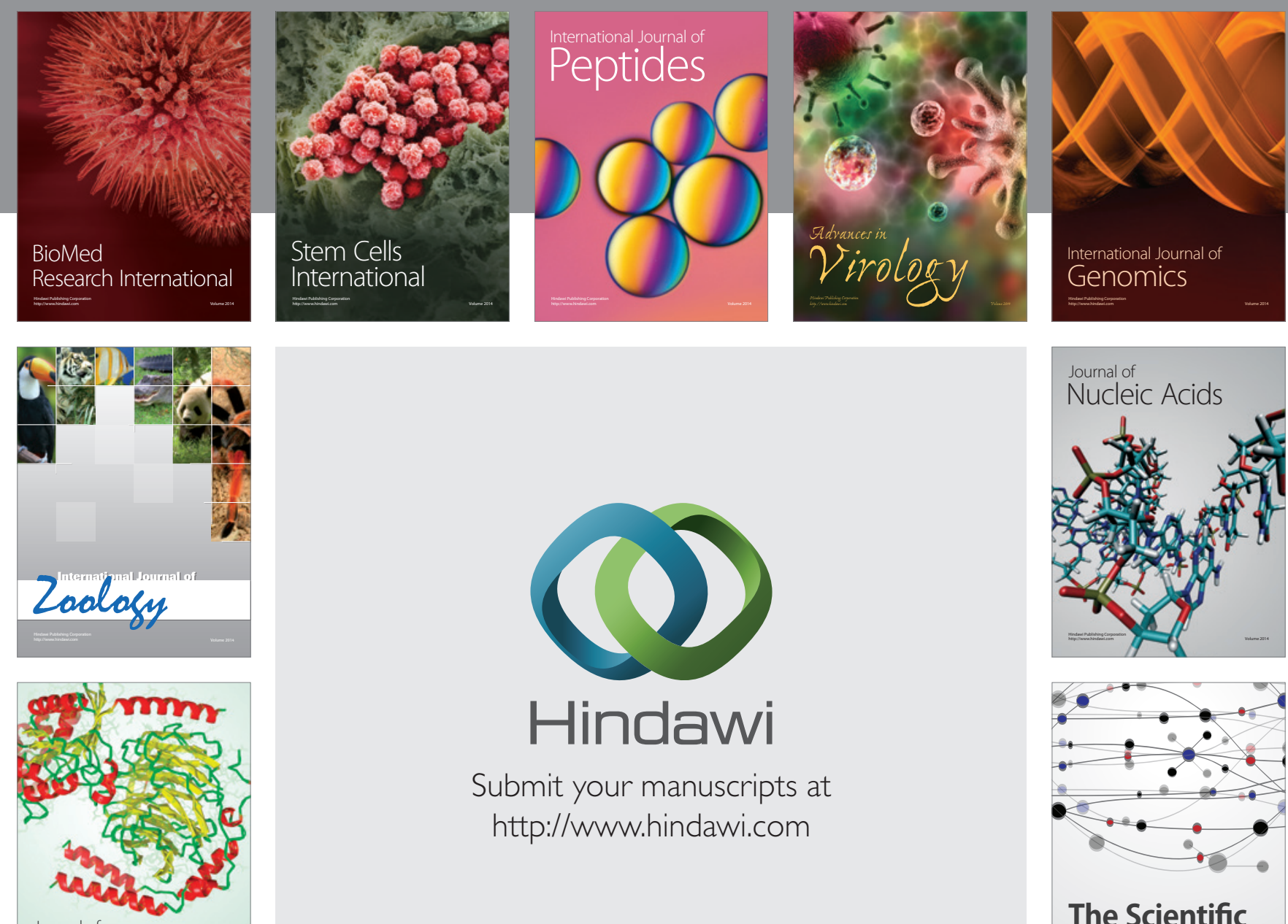

Submit your manuscripts at

http://www.hindawi.com

Journal of
Signal Transduction
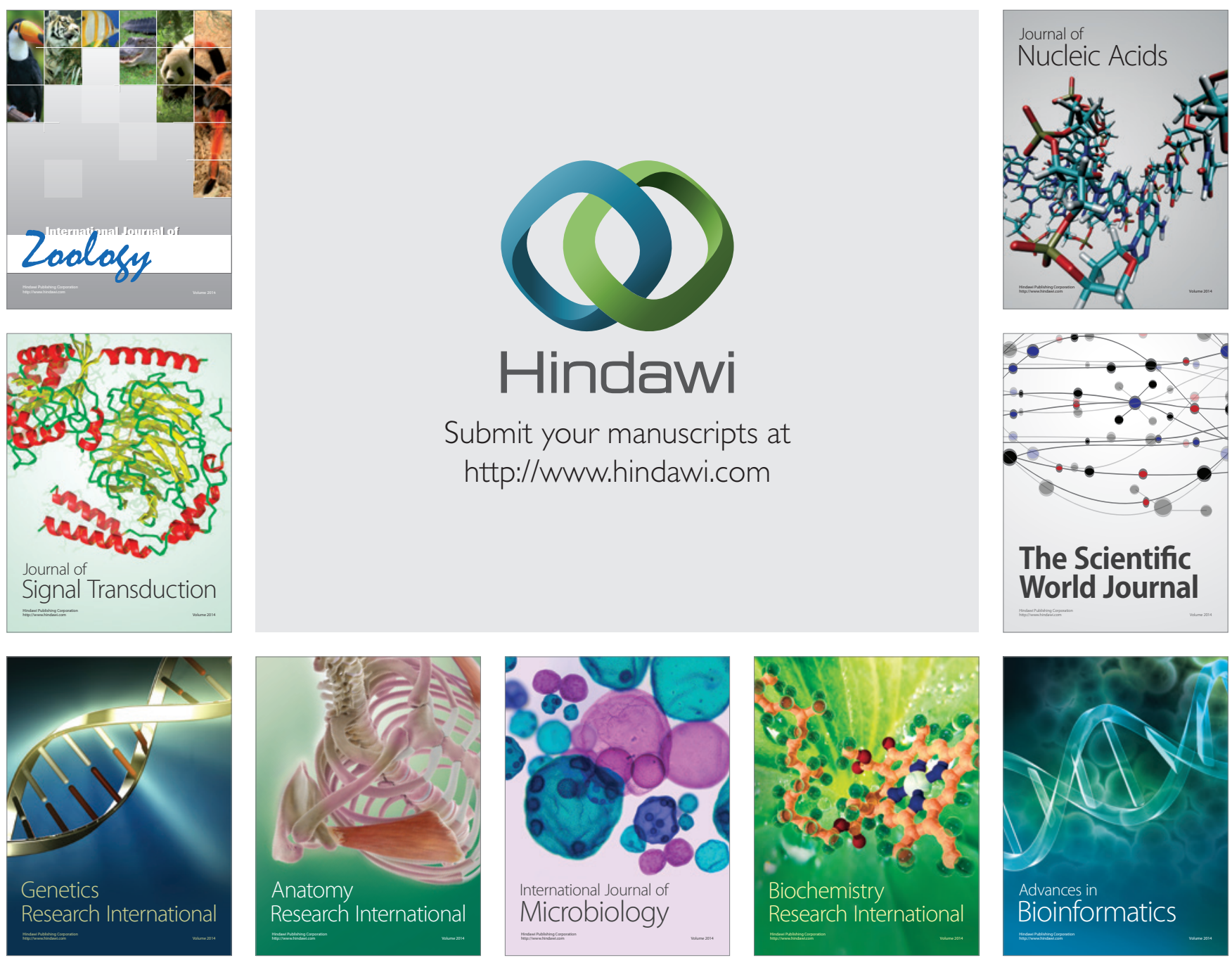

The Scientific World Journal
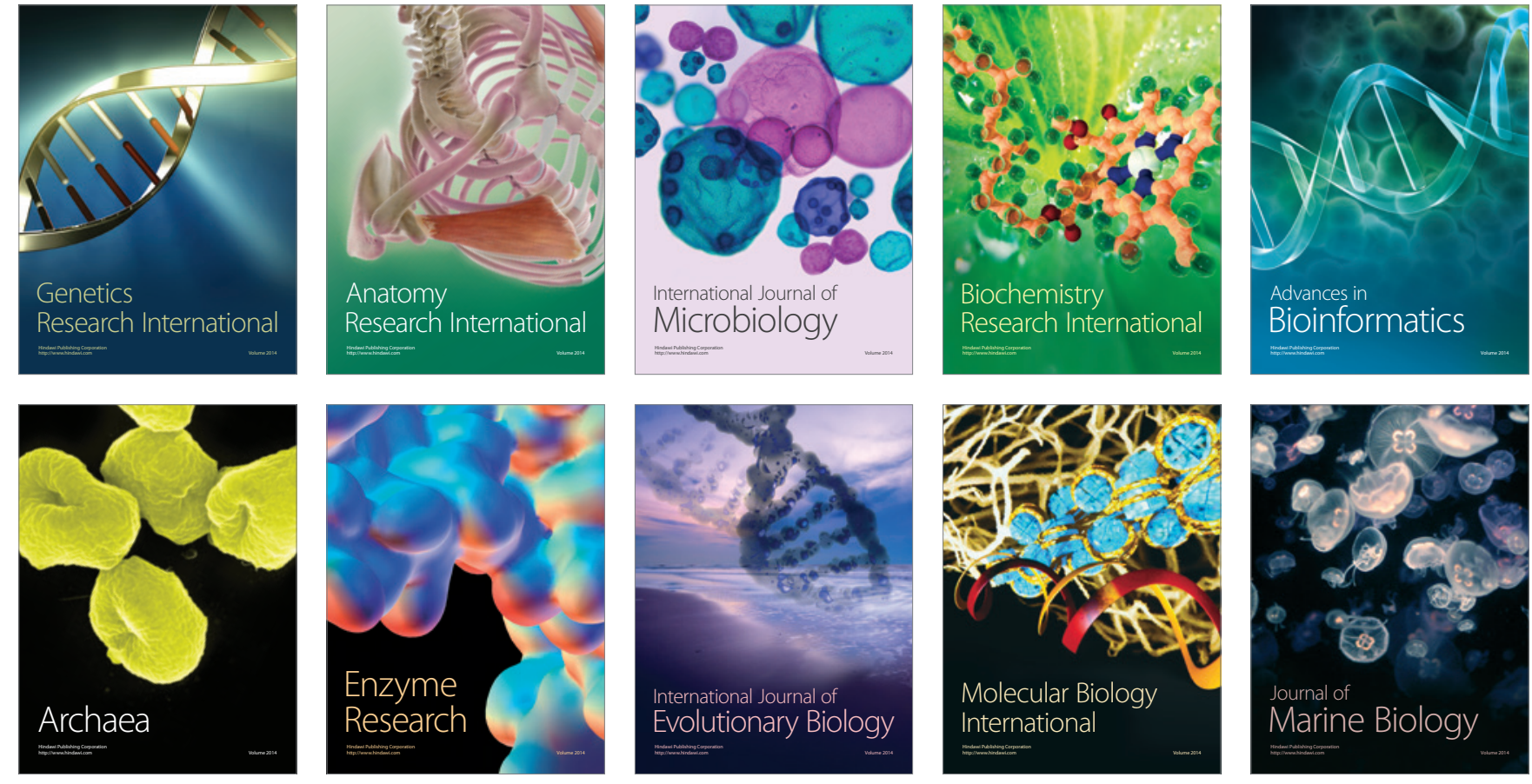